\title{
Bloodstream infection related to the use of central peripheral insertion catheter
}

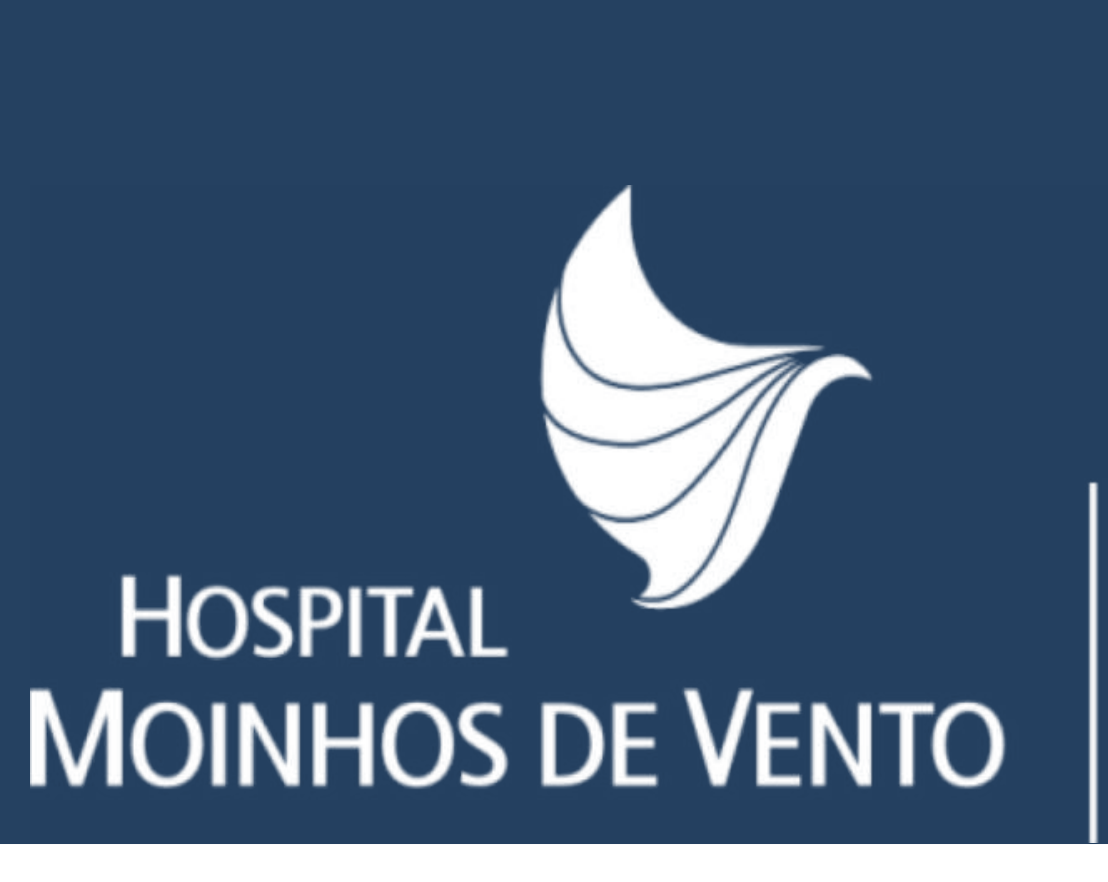

Janaína Flôr; Kássia Cardoso; Giovana Stange; Eduarda Davila; Tiago Maurer; Luciane Finatto; Ana Isabel Martins; Taina Vorkman; Rúbia Maestri

\section{INTRODUCTION}

The central peripheral insertion catheter (PICC) is one of the choices for infusions of drug therapy in adult, pediatric and neonatal patients, presenting a low rate of recurrent puncture complications as well as low rates of catheter-related infections, thus causing greater patient safety1. Studies indicate that the PICC has a decreased infection rate compared to the short-term central venous catheter, reaching $1.3 \% 2$.

\section{OBJECTIV}

To analyze the rate of infection of blood flow to the central peripheral insertion catheter in a private hospital in southern Brazil.

\section{METHODS}

The search was performed through the indicators of the Infection Control Service of the hospital reported in the year 2016. The number of catheters inserted in $\mathbf{2 0 1 6}$ was described, as well as the microorganism responsible for the infection of this catheter, as well as the final rate of infection

\section{RESULTS}

197 PICCs were inserted in 2016 in adult patients admitted to the institution. We have resulted in a rate of bloodstream infection related to the use of this $0.5 \%$ catheter. We had a $6.6 \%$ infection in April (08 catheters were inserted this month) and $2.5 \%$ in July ( 18 catheters were inserted in this month). In the other months we did not have a PICC-related bloodstream infection. $76 \%$ of the inserted catheters were for antibiotic therapy use.

\section{CONCLUSION}

In the target hospital of this study we conclude that the PICC has low rates of bloodstream infection, being a safe option for the infusional therapy prescribed for the patient. 